\title{
Work Culture and Learning Organization Practices in Promoting Work Productivity among Public Elementary School Teachers
}

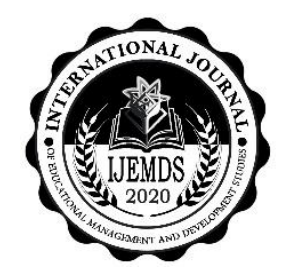

\author{
${ }^{1}$ Vanessa Marie M. Aliazas \& ${ }^{2}$ Elisa N. Chua, PhD
}

\begin{abstract}
The study focused on the extent of work culture and learning organization practices in promoting work productivity among public elementary school teachers at the San Francisco District School System, Division of San Pablo City for the School Year 2020-2021. A total of 163 teacherrespondents were used in the study. Frequency percentage, standard deviation, and the mean were used to assess the level of manifestations among variables. In addition, Pearson correlations were employed to identify positive relationships of work culture and learning organization practices to work productivity. Findings revealed work culture was highly observed and learning organization was highly practiced among public elementary school teachers. Similarly, respondents in the San Francisco District show a high level of work productivity in effective teaching and work commitment. Furthermore, there is a moderate relationship between work productivity and work culture (supportive, innovative, and bureaucratic). Finally, there was a moderate to strong association between learning organizational practices and work productivity. The findings implied that work culture and learning organization practices are critical since they directly impact on attracting and maintaining people. The positive work relationships that occur at the workplace represent a positive environment. As a result of its ability to do so, the school can stay ahead of the curve in terms of change and competition, resulting to higher productivity.
\end{abstract}

Keywords:

work culture, learning organization practices, work productivity

Suggested Citation: Aliazas, V.M. \& Chua, E.N. (2021). Work Culture and Learning Organization Practices in Promoting Work Productivity among Public Elementary School Teachers. International Journal of Educational Management and Development Studies, Volume 2, Issue 3, pp. 39 - 60.

\footnotetext{
About the authors:

${ }^{1}$ Corresponding author. Teacher II, San Gregorio Elementary School

${ }^{2}$ Associate Professor V, Laguna State Polytechnic University- San Pablo City Campus
} 


\section{Introduction}

The term "school" has evolved to mean an educational institution in recent political and educational trends. The ultimate goal of schools is to develop self-directed learners by enhancing the lifelong learning abilities. To achieve this goal, schools must transform from knowledge-transfer institutions to learning organizations. Crucial to this process is the role of teachers.

Teacher's primary goal is to make students learn through the teaching-learning process. As the educational system progresses to cope with global changes, the main responsibility to teach students expands to a more challenging task. The expectations grow from the people under the education umbrella, specifically the teachers, who are in direct contact with the primary stakeholders - the students. Since outcomes are expected, and performance becomes the basis for evaluation, additional works are given to teachers. Reports and other paper works tend to fill in most of the teachers' time. In addition, teachers have hard time achieving subject outcomes due to lack of resources, training, and tools. Nevertheless, the educator must carry on with the learning process by exhausting all possible means to ensure that all students acquire the necessary knowledge.

A well-cultured learning organization like the school can significantly assist the teachers who have difficulty performing their assigned tasks, especially during times of crisis. For instance, situations when more work are required with very limited time minimal time, performance becomes less efficient and effective. In such scenario, it is essential that the school, the school head, and the teaching and non-teaching personnel have a harmonious and motivating environment. The motivation energizes an individual to do what they are expected to do. A person's level of motivation is reflected in his actions and the intensity and duration of his work commitment. An unmotivated or poorly motivated individual has little desire to do things effectively whereas highly motivated individual achieves and performs well. That force can be amplified by something external to the individual, internal to them, or by the activity itself (Bergström E. et al., 2016).

According to Department of Education (DepEd) Order No. 42, series of 2017, titled 'National Adoption and Implementation of the Philippine Professional Standards for 
Teachers', the DepEd is committed to supporting teachers and taking unequivocal evidence that good teachers are critical to raising student achievement. Quality instruction is required for quality learning. As a result, enhancing teacher quality becomes crucial for both job productivity and long-term nation building.

The task of moulding the minds of the youth demands not only sincerity but also diligence, integrity, and professionalism. A good teacher profoundly influences students' lives is not lost beyond the school (Tomlinson, 2014). A good teacher is a good person who has a wholesome and motivating influence on young people by their personality, character, and attitudes. Several elements influence a teacher's work performance, such as their desire to do the job, their capacity to do it, and the time required to work in the workplace environment. A work culture becomes effective and efficient to their duty as a teacher. Identifying the elements that influence teacher's productivity could serve as a foundation for developing effective and committed learning organizations.

\section{Literature review}

\subsection{Learning Organizations}

According to Peter Senge's (2014) idea of learning organizations, everyone impacts the system's success, and organizations can only learn through individuals who understand. The Senge management theories are well-known academic theories that focus on establishing learning environments for leaders and subordinates. Accordingly, learning organizations create an environment in which people are interested in their job and dedicated to the organization's vision. Individual learning does not indicate that an entire organization will learn. Organizational learning, on the other hand, does not occur without it. The primary rationale for such organizations is that only flexible, adaptable, and productive would succeed in conditions of fast change. It is proposed that organizations create ways to tap people's commitment and capacity to learn at all levels for this to happen.

While everyone can learn, the institutions must operate are frequently inhospitable to reflection and participation. People may also lack the skills and guiding principles needed to make sense of the situations they find themselves in. Organizations that constantly extend 
their power to shape the future require a fundamental transformation in their members' mind sets.

Figure 1

Five Disciplines by Peter Senge

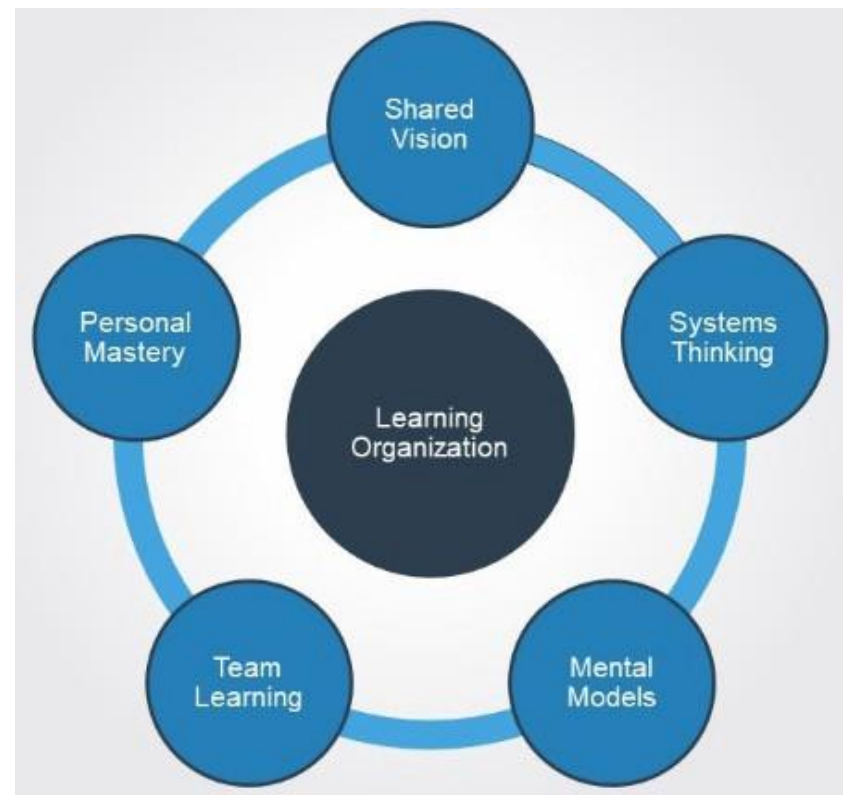

Source: Senge's Five Disciplines of Learning Organizations. (2017, November 7). Retrieved June 17, 2021, from toolshero website: https://www.toolshero.com/management/five-disciplines-learning-organizations/

According to Peter Senge, real learning gets to the heart of what it is to be human. People are given the ability to re-create themselves. This is true for both individuals and businesses. As a result, simply existing is insufficient for a learning organization. Survival learning, sometimes known as "adaptive learning," is vital; it is required. However, "generative learning," or learning that improves the ability to produce in a learning organization (Senge, 2014) must supplement "adaptive learning".

According to Peter Senge, institutions are locations where people continually improve their ability to achieve the targeted outcomes. In this place, people cultivate new and broad forms of thought, a place where common desire is unrestrained and a place where people learn to perceive the entire collection. The primary rationale for such institutions is that people who do not oppose are productive and adaptable in times of rapid transformation. It is 
reasoned that businesses must understand how to tap into people's confidence and ability to learn at all levels (Chang \& Sun, 2007).

Proper education reaches the human heart. Humans gain the ability to rebuild themselves, and this applies to organizations as well. Rather than imagining a typical hierarchy, today's institutions can thrive by establishing a learning organization. People in a business are constantly expanding their potential to achieve the outcomes they desire. It is where people are continually learning how to study together, where new and broader thought patterns are developed, and where collective aspiration is set free (Zeeman, 2017). Senge's ability to master the core five disciplines, including mental models, personal mastery, systems thinking, developing a shared vision, and team learning, characterizes learning from native institutions. Senge's five disciplines of learning organizations, often known as Senge's learning organization, outline how to manage an organization's success and development and how people go above and beyond the company's objectives. People are agents who operate on these systems and arrangements (Senge, 2014).

If the emphasis is placed on daily tasks that individuals complete, Bratton \& Gold's (2012) human resource management theory and practice hold up the possibility of increased organizational productivity and member satisfaction. Because it was designed to be integrated into strategic planning, Human Resource Management (HRM) represents a new way to managing people. HRM models also refer to performance outcomes, suggesting that a cohesive set of practices will boost teachers' commitment and performance amid the $21^{\text {st }}$ century challenges. The work productivity construct may have anything to do with successful instruction and work commitment. Effective teachers attempt to motivate and engage all of their pupils in learning not accepting kids who are uninterested will perform poorly. Teachers think that every student can succeed in school and will do everything to help each student succeed (O'Neill, 2009). Work commitment, like any other type of connection, is at the heart of a healthy one. People who are passionate about their work and their employers are more likely to be happy and productive. Committed employees take ownership of their careers and serve as ambassadors for their organizations both inside and outside the office (Marzullo, 2019). 


\subsection{Organizational Culture and Leadership}

Any organization's culture is essential, but it's tough to develop a single, uniform description. According to Schein (2010), a pattern of shared basic assumptions learned by a group as it solved difficulties through external adaptation and internal integration that has proven to be legitimate and, thus, to be instilled in new members as the proper way of perceiving, thinking, and feeling about those problems. The three levels of an organization's culture are artefacts, proclaimed ideas and ideals, and basic underlying assumptions (Schein, 2010). Artefacts can be found in the institution's physical facilities, employees' outward behaviors, and how work is structured and processed. Artefacts can be linked to the explicit knowledge of an organization. Individual ideals, principles, and personal objectives can be found in the organization's stated vision, mission, and goals and exceptional standards, directions, and personal goals. This level of culture reveals itself in both explicit and implicit knowledge. At the cultural level, basic underlying assumptions constitute the unspoken thoughts, attitudes, and perceptions that influence decision-making and employee behavior (Schein, 2010). This level of culture refers to tacit knowledge, an intangible aspect of an organization that is difficult to explain.

Workplace culture is a complex and multifaceted phenomenon. Filipinos take pride in their profession and emphasize developing relationships with others to better provide for their families and the success of their institutions. If learning is to occur, new ideas are required, and these ideas are the catalyst for organizational change (Howard-Grenville et al., 2014). Workplace culture is concerned with how people create teams and collaborate to achieve success. Employees make decisions to enhance value while taking into account their social and cultural context. Employees' social cohesion is based on their culture. Internal governance and decision-making are governed by it, and it is an organization's distinguishing trait.

The current study sought to determine the work culture and learning organization practices in promoting work productivity among public elementary school teachers. Precisely, it aims to (1) determine the extent of work culture observed among schools regarding supportive, innovative, and bureaucratic culture; (2) determine the learning organization practices of public elementary teachers regarding shared vision, team learning, 
systems thinking, personal mastery, and mental models; (3) determine the extent of manifestation of work productivity as to effective teaching, work commitment, and work performance; and (4) determine the significant relationship of work productivity to work culture and learning organization practices.

\section{Methodology}

The descriptive research method was applied in this study. It aimed to characterize the data and do a correlational analysis of the several variables, particularly on teachers' work culture and learning organization practices. The study's goal is to obtain a precise assessment of the objectives from each of its components. A descriptive technique was allowed because this study aimed to determine the work productivity of public elementary school teachers.

The study was conducted in the Division of San Pablo City, particularly in the district of San Francisco, encompassing eleven (11) public elementary schools. There are 163 public elementary teachers who served as respondents of the study. The purposive sampling technique was used for the sample selection.

The main data-gathering instrument was a researcher-made questionnaire. There were three sets of questionnaire checklist to obtain data from school-selected teachers. The questionnaire checklist was divided into two sets of variables: work culture characterizing its three types (supportive, innovative, and bureaucratic culture) and the five disciplines in the learning organization practices. The rating was based on the teacher-respondents' level of agreement on each given statement of organizational productivity indicating effective teaching, work commitment, and school performance.

The research instrument's internal and external validation ensured that the indicators appropriately represent the variables. Seven (7) experts from different schools served as the external validators. After validating the instrument, it was tested for reliability and internal consistency (Table 1) through pilot testing of ten (10) teacher- respondents. Due to the ongoing COVID-19 pandemic, the instrument was converted to a Google form for efficient distribution. 


\section{Table 1}

Reliability Statistics Results

\begin{tabular}{|c|c|c|c|}
\hline & $\begin{array}{c}\text { Cronbach's } \\
\text { Alpha }\end{array}$ & $\begin{array}{l}\text { Number } \\
\text { of Items }\end{array}$ & $\begin{array}{c}\text { Verbal } \\
\text { Interpretation }\end{array}$ \\
\hline \multicolumn{4}{|l|}{ Work Culture } \\
\hline Supportive Culture & 0.921 & 10 & Excellent \\
\hline Innovative Culture & 0.937 & 10 & Excellent \\
\hline Bureaucratic Culture & 0.898 & 10 & Good \\
\hline \multicolumn{4}{|l|}{ Learning Organization Practices } \\
\hline Shared Vision & 0.927 & 5 & Excellent \\
\hline Personal Mastery & 0.888 & 5 & Good \\
\hline Team Learning & 0.889 & 5 & Good \\
\hline Mental Models & 0.859 & 5 & Good \\
\hline Systems Thinking & 0.875 & 5 & Good \\
\hline \multicolumn{4}{|l|}{ Effective Teaching } \\
\hline Dispositions & 0.963 & 10 & Excellent \\
\hline Teaching Competence & 0.871 & 10 & Good \\
\hline Pedagogical Knowledge & 0.938 & 10 & Excellent \\
\hline \multicolumn{4}{|l|}{ Work Commitment } \\
\hline Job Enablement & 0.938 & 5 & Excellent \\
\hline Performance and Accountability & 0.873 & 5 & Good \\
\hline Strategic Alignment & 0.931 & 5 & Excellent \\
\hline Work Processes & 0.943 & 5 & Excellent \\
\hline
\end{tabular}

The gathered data are interpreted and analyzed using the appropriate statistical tools. Standard deviations were employed to determine further the homogeneity of the collected responses on the study's variables. Mean was used to describe the perceptions of the respondents in the structured questionnaire devised by the researcher. The Pearson-r correlation was utilized to define the extent of work culture and learning organization practices and how it may have affected work productivity among public elementary teachers.

\section{Findings and Discussion}

Table 2 entails the extent of work culture being observed in school. Workplace culture and climate are intangible but critical aspects of a school's working environment. It was revealed that the school-adapted learning modalities fitted to the changing learning environment were deemed highly observed $(\overline{\mathrm{X}}=3.83 ; \sigma=0.332)$. In the performance of SBM following DepEd Memo, students and employees benefit from a supportive work culture 
because it creates a safe, supportive, encouraging, inviting, and challenging workplace, allowing work productivity to improve. This highly observed supportive culture is present in most elementary schools included in the study. The teachers, parents, and heads work together to accomplish tasks such as preparing, distributing, and retrieving modules.

\section{Table 2}

The Extent of Work Culture Observed among public elementary schools

\begin{tabular}{lccc}
\hline \multicolumn{1}{c}{ Work Culture } & Mean & SD & $\begin{array}{c}\text { Verbal } \\
\text { Interpretation }\end{array}$ \\
\hline Supportive Culture & 3.82 & 0.332 & $\mathrm{HO}$ \\
Innovative Culture & 3.77 & 0.359 & $\mathrm{HO}$ \\
Bureaucratic Culture & 3.70 & 0.349 & $\mathrm{HO}$ \\
\hline
\end{tabular}

Legend: 3.26-4.00 Highly Observed (HO;) 2.51-3.25 Moderately Observed (MO); 1.76-2.50 Seldom Observed (SO); 1.001.75 Rarely Observed $(R O)$

This study consistently acknowledged interventions and strategies for fostering a positive work culture in primary schools. However, the key to their success in this endeavor is to change the entire culture, not just isolated components of school systems (Latta, 2009). In addition, the results entail that most respondents highly observed that the school encourages teachers to give suggestions for school improvement. As a result, teachers were constantly grappling with change as they attempted to relate the needs of students to the larger community.

In a school setting, an innovative work culture necessitates frequent communication with coworkers. While technology does not always inspire creativity in the classroom, it can help. The Covid-19 pandemic has spawned many new ideas for employing technology and other key tools to improve teaching and student engagement. Furthermore, school stakeholders, particularly teachers, must create innovative ways to interact with parents and meet the needs of pupils. As a result, it's critical to concentrate on new developments in child psychology, learning theories, and teaching approaches. Overall, the extent of innovative work culture perceived among teacher-respondents was highly observed $(\bar{X}=3.77 ; \sigma=0.359)$. The way the staff dresses what teachers talk about in the faculty room, their teaching methods, and their readiness to change are all influenced by the culture at school (Harris \& Bennett, 2005). These adjustments create a relational trust that functions as glue, allowing 
stakeholders to connect and think that each member is doing their part to improve the school (Zmuda, 2004).

The level of the respondents' observations on bureaucratic work culture was regarded highly observed, with their school providing a place where accountability is required. Both positive and negative characteristics of bureaucratic school structures exist (Mitchell, 2020). This construct, on the other hand, is not static and may be examined from various angles. The authority was typically focused on top management in this study's bureaucratic school system among elementary schools. Information frequently flows down from the division level to the school level, promoting a monitor and order mentality in which functioning practices are strictly monitored and managed.

Overall perception reveals that bureaucratic work culture is highly observed among the San Francisco district elementary schools $(\overline{\mathrm{X}}=3.70 ; \sigma=0.349)$. The study's findings revealed that the effectiveness level of the bureaucratic work culture was highly observed among the study's teacher respondents. Teacher leadership culture is occupational, cooperation, school administrator support, and a supportive working environment (Cansoy \& Parlar, 2017). The efficacy of the bureaucratic work culture was found to describe the school head's support behavior, caring work environments, and work-related teamwork environment, which are all factors that influence primary teachers' work productivity. According to the results of the respondents' survey, school administrators' positive and collaborative manners and work-related, organizational, and institutional aids can help teachers enhance their leadership skills.

Table 3 shows the extent of the learning organization practices among schools. The results show that most of the respondents, as school members, believe in the organization's work. Shared vision as dimensions of learning organization helps elementary school teachers to perform efficiently with their clientele (Kaiser, Fahrenbach, \& Martinez, 2021). Using these approaches, it is possible to effectively motivate and encourage the school management unit to generate a true vision and mission and increase performance and harmony. Overall, shared vision is highly practiced among teacher-respondents in a learning organization $(\bar{X}=3.83 ; \sigma=0.315)$. Between school leaders and teachers in the school, the linkages between members' shared vision of the school's aims and many communication-related activities were 
vital. According to the theory, teachers who believe in the organization's mission are more likely to attain a shared vision. The findings should be helpful to school leaders, and management in determining the most effective methods for sharing organizational learning.

\section{Table 3}

The Extent of Learning Organization Practices of Public Elementary Teachers

\begin{tabular}{lccc}
\hline \multicolumn{1}{c}{ Learning Organization Practices } & Mean & SD & $\begin{array}{c}\text { Verbal } \\
\text { Interpretation }\end{array}$ \\
\hline Shared Vision & 3.83 & .315 & $H P$ \\
Personal Mastery & 3.84 & .318 & $H P$ \\
Team Learning & 3.83 & .318 & $H P$ \\
Mental Models & 3.83 & .327 & $H P$ \\
Systems Thinking & 3.84 & .316 & $H P$ \\
\hline Legend: 3.26-4.00 Highly Practiced (HP); 2.51-3.25 Moderately Practice (MP); 1.76-2.50 Seldom Practiced (SP); 1.00- \\
$\quad$ 1.75 Rarely Practiced (RP)
\end{tabular}

1.75 Rarely Practiced $(R P)$

The extent of practice on personal mastery in a learning organization shows that the majority of the respondents value a healthy, balanced, disciplined, and resilient life as highly practiced among schools of the San Francisco district. Perhaps the most elusive of the five elements of a learning organization is personal mastery. It has a lot to do with public elementary teachers' "self-awareness," which is defined as performing inner-work on oneself and seeing how patterns of thinking, feeling, and behaving affect the people and situations in the school. The overall extent of practice among teacher-respondents highly practiced personal mastery in a learning organization $(\overline{\mathrm{X}}=3.84 ; \sigma=0.318)$. Teachers who practice the dimensions of personal mastery utilize them as an individual basis to find purpose in their work and be productive. It acts as a mooring buoy, anchoring teachers to their mission and preventing them from floating away from what matters due to organizational tides (Cropper et al., 2018).

Team learning practices among teachers show that they practiced professionalism in working with colleagues as school members. It was found that organizational contexts emphasizing professionalism and collaborative work among elementary teachers increase team learning. Likewise, those emphasizing responsiveness and knowledge management in meeting deadlines and targets increased team learning. As practice by public elementary teachers, team learning influenced both task performance and the quality of interpersonal 
relations. The result further shows that learning organizations among the schools of the San Francisco district highly practiced team learning $(\overline{\mathrm{X}}=3.83 ; \sigma=0.318)$. According to Boon et al. (2018), team learning has predictive value for various team performance metrics as reported by team members and managers. As a result, to improve their performance, the team should adequately plan their learning process.

In terms of mental models, the learning organization practices among schools demonstrated that respondents act following the organization's requirements. Individuals are frequently used as the unit of analysis in mental models. The group's cognitive functions were spread evenly. For the most part, most people practiced value camaraderie and satisfying relationships. The importance of mental models in a learning organization, according to Burtscher and Manser (2012), demonstrates team members' shared and organized grasp of essential knowledge and focuses on the tasks and difficulties inherent in the workplace. Overall, the teacher-respondents highly practiced $(\overline{\mathrm{X}}=3.83 ; \sigma=0.327)$ mental models as a dimension of a learning organization. Regardless of school sizes, teachers often work with one another, and the result has been highly practiced among San Francisco district schools. From lesson planning, assessment strategies, management approaches, and others, mental models as dimensions of the learning organization have been transforming classrooms and schools that are genuinely committed to seeing equitable outcomes for the students.

Majority of the respondents' perceptions value respect for one's work. A system thinking observed in the study is the interactions amongst teachers, students, school leaders, and the learning goals. The results illustrate teachers' practices in the school to support the organization's vision and goals. The overall perception of a learning organization as systems thinking is deemed highly practiced $(\overline{\mathrm{X}}=3.84 ; \sigma=0.316)$. Schools, districts, and classrooms are high-energy, high-talent places. Managing them necessitates innovative leadership and educational methods. Teachers who want to increase student engagement can use systems thinking as a tool. The method also aids school leaders in organizing their facilities by utilizing their advantages. 


\section{Table 4}

The Extent of Work Productivity Manifestation in terms of Effective Teaching

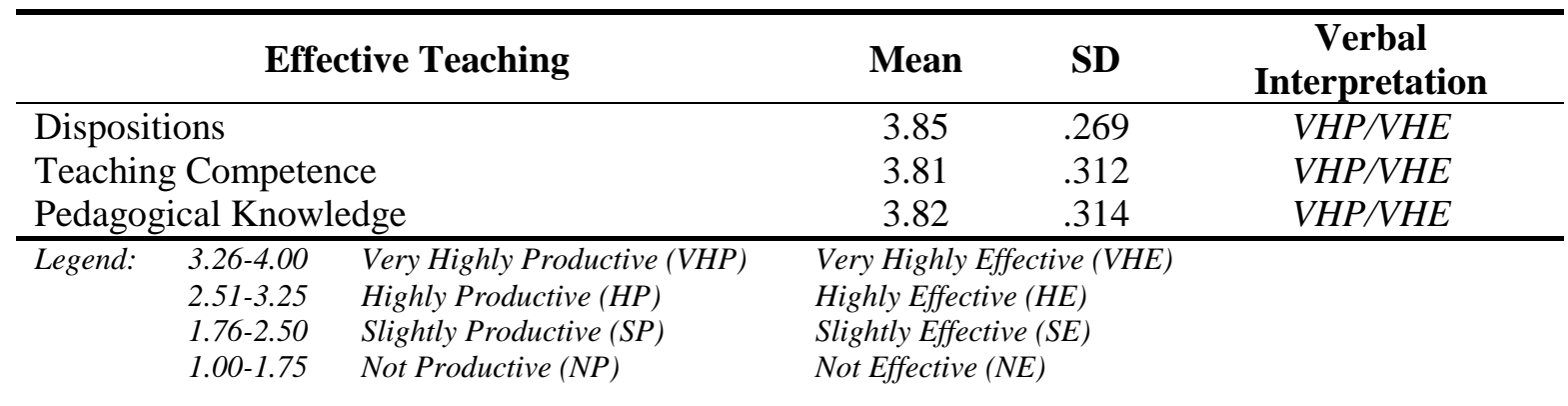

Table 4 elicits the extent of work productivity among teacher-respondents in terms of effective teaching. It was revealed that the respondent committed to student learning and demonstrated positive rapport, contributed to group efforts, and showed respect for other ideas. As well as demonstrate professional appearance, ethical/ legal practices, and professional demeanor. Giovanelli (2010) found that a positive teaching attitude was linked to effective teaching and increased work productivity, particularly instructional behavior, classroom organization, and instructor expectations. Overall, teacher-respondent perceived effective teaching in terms of disposition as Very Highly Productive ( $\overline{\mathrm{X}}=3.88 ; \sigma=0.269)$. As determined by their administrators, effective teachers establish classroom methods and actively involve their pupils in learning to help them achieve educational success (Tulgar, 2005). The attitude of elementary teachers in the San Francisco district is constant in following established norms and procedures while doing their duties, resulting in instructional flow as pupils stay on track. Teachers find ways to communicate with their pupils through practical verbal and nonverbal communication skills and create rapport. Their emphasis on teaching appears to be linked to effective classroom management, which boosts organizational productivity. Teachers display flexibility and adaptation in conducting remote learning through the DepEd blended learning modality. These educators are dedicated to assisting children in learning through repetition, communicating effectively, and engaging students in active listening to ensure that concepts and skills are understood.

According to effective teaching in teaching competence, teachers urge learners to embrace unexpected changes in the learning process. Teachers, however, pay attention and reply clearly to the questions posed. The outcome can be linked to the teacher's professional 
competence, work discipline, and productivity at work. Overall results $(\overline{\mathrm{X}}=3.81 ; \sigma=0.312)$ suggest that teaching competence is very highly productive among teacher-respondents of the study. According to Nisa (2020), future issues will necessitate teachers to increase their work productivity. It explains and evaluates professional competence's direct and indirect contributions to work productivity through work discipline and instructor performance. Teachers' professional abilities in effective and compassionate communication, collaborative teamwork, and impactful stakeholder involvement are critical to DepEd's aims. It critically examines moral development's efficacy and obstacles. These professional talents go beyond topic knowledge and methodological competence, making it easier for students to pick up these skills.

Learning is a cyclical process, and each failure is an opportunity to learn a new strategy. There is very high productivity on the teacher respondents perceived cooperation and participation in all activities and programs of the school. Improving students' educational results necessitates schools' learning organizations in which both students and teachers participate in learning. As a result, pedagogical knowledge and discussion must be at the heart of school professional culture. The overall results indicate that very high work productivity in terms of pedagogical knowledge as a construct of effective teaching was manifested $(\overline{\mathrm{X}}=3.82 ; \sigma=0.314)$. In this context, a focus on pedagogies, which thinks that quick feedback is the most effective approach for achieving mastery, can make a difference in students' academic and social outcomes. According to Sellar \& Lingard (2013), teachers and administrators, school systems, and community groups involved in learning organizations should be concerned about such pedagogical practices.

\section{Table 5}

The Extent of Work Productivity Manifestation in terms of Work Commitment

\begin{tabular}{|c|c|c|c|c|c|}
\hline \multicolumn{3}{|c|}{ Work Commitment } & Mean & SD & $\begin{array}{c}\text { Verbal } \\
\text { Interpretation }\end{array}$ \\
\hline \multicolumn{3}{|c|}{ Job Enablement } & 3.90 & .268 & $V H P / V H E$ \\
\hline \multicolumn{3}{|c|}{ Performance and Accountability } & 3.88 & .281 & $V H P / V H E$ \\
\hline \multicolumn{3}{|c|}{ Strategic Alignment } & 3.86 & .321 & $V H P / V H E$ \\
\hline \multicolumn{3}{|c|}{ Work Processes } & 3.87 & .289 & $V H P / V H E$ \\
\hline Legend: & $\begin{array}{l}3.26-4.00 \\
2.51-3.25 \\
1.76-2.50 \\
1.00-1.75\end{array}$ & $\begin{array}{l}\text { Very Highly Productive (VHP) } \\
\text { Highly Productive }(H P) \\
\text { Slightly Productive }(S P) \\
\text { Not Productive }(N P)\end{array}$ & $\begin{array}{l}\text { Very Highly } \\
\text { Highly Effect } \\
\text { Slightly Effec } \\
\text { Not Effective }\end{array}$ & $\begin{array}{l}\text { ve }(V H E) \\
E) \\
E) \\
E)\end{array}$ & \\
\hline
\end{tabular}


Table 5 shows the extent of work productivity among the schools in the district of San Francisco, addressing work commitment. The results elicit that teachers are proud to work for the school, which shows very high productivity. Job enablement's strategic importance has become a high-profile phenomenon, high on organizational agendas, and well-known among school administrators. As a result, the overall display is deemed very highly productive $(\bar{X}=3.90 ; \sigma=0.268)$. Ability management and retention have become essential in work commitment strategy, and job enablement is a viable solution. The school workplace moves teachers beyond the stage of just being engaged with the DepEd goals and their interest in the product. Instead, it provides guidance and empowers teachers to continue learning, developing, and getting the necessary training to deliver quality results (Radda, Majidadi, \& Akanno, 2015). The findings reveal a relationship between primary teacher involvement and favorable school outcomes and performance. Every organization wants to keep its teachers, avoid high faculty turnover, and improve student results.

Elementary teachers in this study believe that they are accountable for their performance. Schools maintain their value, belief, and culture and thus the stability of the organization. The impacts of performance-based school reforms and school change from different perspectives reflect the institutions' quality assurance. The result suggests that performance and accountability as a construct of work commitment among public elementary teachers in the district of San Francisco were deemed very highly productive, reflecting institutional performance.

Performance and accountability show a very highly productive work commitment $(\bar{X}=3.88 ; \sigma=0.281)$ among teacher-respondents of the study. Results provide needed incentives for teachers to improve performance. Performance and accountability can generate suggestions and speculative for enhancing the conditions faced by teachers modifying system approaches for student improvement.

The findings suggest that schools in the district of San Francisco provide an opportunity for professional learning and development. Likewise, it also observes that the school head's behavior is aligned with the school's values. It reveals how the strategic alignment $(\overline{\mathrm{X}}=3.86 ; \sigma=0.321)$ of teacher capabilities with school requirements has influenced work productivity throughout school development. The intricate linkages between teacher 
commitment to their professions, such as motivation, opportunity, and aims, were studied. Strategic alignment is highly effective among elementary teachers in the San Francisco district, revealing that work productivity performance necessitated many prioritized actions, including school leaders and changes in organizational practices relating to student progression improvement.

It was revealed that the work process is well-coordinated among the teaching staff. The results also support that work commitment in terms of the work process is very highly productive $(\overline{\mathrm{X}}=3.87 ; \sigma=0.289)$ among the respondents. The teachers were found to be effective throughout their design process, and as a result, their work process capacity switched from adapting or distributing to designing their programs. These findings are essential for primary school teachers because they emphasize the necessity of young teachers' complex, exploratory, integrative, and diversified curricular teaching-learning experiences (Trinter \& Hughes, 2021). If public elementary teachers developed these kinds of experiences for their pupils and encouraged them to discover better ways of accomplishing jobs, they would provide better experiences for them.

Based on the Individual Performance Commitment and Review Form (IPCRF) assessment, Table 6 demonstrates the level of teacher work performance. DepEd is committed to giving individuals of the organization chances to connect their accomplishments and contribute meaningfully to the institution's vision and goal. An organization's performance management is critical. It encourages personal and team development, engagement, and dedication. IPCRF stresses the DepEd thrusts' strategic alignment with day-to-day operations. According to Comighud (2019), public schools have many goal setting, monitoring, and feedbacking methods that support professional and personal growth.

\section{Table 6}

Teacher's Work Performance Level (IPCRF)

\begin{tabular}{cccc}
\hline IPCRF Rating & Frequency & Percent & Level \\
\hline $4.500-5.000$ & 15 & 9.2 & Outstanding \\
$3.500-4.499$ & 142 & 87.1 & Very Satisfactory \\
$2.500-3.499$ & 6 & 3.7 & Satisfactory \\
$1.500-2.499$ & - & - & Unsatisfactory \\
Below 1.499 & - & - & Poor \\
\hline Total & $\mathbf{1 6 3}$ & $\mathbf{1 0 0}$ & \\
\hline
\end{tabular}


The result reveals that most of the teachers were rated very satisfactory, accounting for $87.1 \%$ of the total respondents of the study. Teachers in San Francisco's public elementary schools are proficient in 21st-century skills and job performance. Likewise, $9.2 \%$ percent of the respondents were rated outstanding based on the given IPCRF rating. Because they are all rooted in the Department of Education's road map, teacher skills complement the IPCRF and can be an ideal tool for assessing job performance promises.

\section{Table 7}

Test of Correlation between Work Culture and Work Productivity

\begin{tabular}{lccc}
\hline \multirow{2}{*}{ Work Productivity } & \multicolumn{3}{c}{ Work Culture } \\
\cline { 2 - 4 } Effective Teaching & Supportive & Innovative & Bureaucratic \\
$\quad$ Dispositions & $0.521^{* *}$ & $0.577^{* *}$ & $0.490^{* *}$ \\
Teaching Competence & $0.447^{* *}$ & $0.519^{* *}$ & $0.487^{* *}$ \\
Pedagogical Knowledge & $0.512^{* *}$ & $0.595^{* *}$ & $0.541^{* *}$ \\
\hline Work Commitment & & & \\
Job Enablement & $0.543^{* *}$ & $0.555^{* *}$ & $0.513^{* *}$ \\
Performance \& & $0.445^{* *}$ & $0.461^{* *}$ & $0.418^{* *}$ \\
Accountability & $0.476^{* *}$ & $0.525^{* *}$ & $0.529^{* *}$ \\
Strategic Alignment & $0.524^{* *}$ & $0.532^{* *}$ & $0.470^{* *}$ \\
$\quad$ Work Processes & - & - \\
\hline Work Performance & - & & - \\
$\quad$ Teachers' Performance & - &
\end{tabular}

Table 7 shows the relationship between perceived work culture and the three work productivity constructs. The findings show that all sub-variables under effective teaching have a strong relationship with the work culture. The results support Almy \& Tooley's (2012) research, which found that, like most other professionals, their sentiments about their careers and decisions about where to teach are heavily influenced by their work surroundings. Despite the widespread notion that students are the primary source of teacher satisfaction and attrition, research shows that the school environment, namely the quality of leadership development and staff cohesion, is more essential, especially for teachers, particularly in public schools.

Secondly, the three constructs of work culture also significantly correlate with work commitment. Professional commitment is described as the potential importance of identifying with and interest in one's profession (Cohens, 2003). According to DeMarco's 
(2018) data analysis, school culture was examined on the surface through the dimensions of planning, staff development, program creation, and productivity assessment. However, the interconnected nature of crucial process and structure factors was revealed by the underlying core assumptions of school culture. Collaboration, participatory decision-making, and supportive administrative leadership were among the strategies used. The designs included stimulating creativity and contingency, school goals and preparation, and capacity building to achieve the goals. According to the findings, organizational structure and process characteristics are positively associated with essential teacher attitudes, including personal efficacy and organizational commitment.

Additionally, district schools view excellent teaching and learning environments as critical tools for attracting, developing, and retaining good teachers in public schools. While each district's approach is different, standard features include a focus on effective leadership, a school commitment to improving education by assessing student data and remarking on practice, and a cooperative environment that values and recognizes individual contributions (Almy \& Tooley, 2012).

Finally, there is no link between work culture and teacher performance, according to the findings. As a result, the findings contradict Hartiwi, Kozlova, and Masitoh's (2020) data, which claim that instructors and principal leadership significantly impact teachers' performance, either partially or concurrently. The difference in nature of the teacher's performance in terms of IPCRF rating could explain the outcome. In this study, teachers' IPCRF ratings had no direct impact on work culture in San Francisco district elementary schools. Furthermore, job satisfaction is necessary for a teacher's work performance, and the IPCRF solely assesses instructors' commitment to their anticipated work outputs.

Learning organization was found to be a strong correlate of effective teaching. Table 8 depicts the association between the learning organization's five dimensions and the three work productivity components. The findings are consistent with Manlow's (2010) study, which reveals that the confluence of disciplines and many interdisciplinary and multidisciplinary activities, both scholarly and curricular, are primary incentives for developing a learning organization in academia. Furthermore, new media may effectively 
drive a company's transformation into a proper learning organization due to its reliance on instantaneous and rapid interconnected and collaborative communication.

\section{Table 8}

Test of Correlation between Learning Organization Practices and Work Productivity

\begin{tabular}{|c|c|c|c|c|c|}
\hline \multirow[b]{2}{*}{ Work Productivity } & \multicolumn{5}{|c|}{ Learning Organization } \\
\hline & $\begin{array}{l}\text { Shared } \\
\text { Vision }\end{array}$ & $\begin{array}{l}\text { Personal } \\
\text { Mastery }\end{array}$ & $\begin{array}{c}\text { Team } \\
\text { Learning }\end{array}$ & $\begin{array}{l}\text { Mental } \\
\text { Models }\end{array}$ & $\begin{array}{l}\text { Systems } \\
\text { Thinking }\end{array}$ \\
\hline \multicolumn{6}{|l|}{ Effective Teaching } \\
\hline Dispositions & $0.630 * *$ & $0.632 * *$ & $0.680 * *$ & $0.667 * *$ & $0.625 * *$ \\
\hline Teaching Competence & $0.571 * *$ & $0.617 * *$ & $0.659 * *$ & $0.673 * *$ & $0.602 * *$ \\
\hline $\begin{array}{l}\text { Pedagogical } \\
\text { Knowledge }\end{array}$ & $0.619 * *$ & $0.646 * *$ & $0.706 * *$ & $0.738 * *$ & $0.712 * *$ \\
\hline \multicolumn{6}{|l|}{ Work Commitment } \\
\hline Job Enablement & $0.754 * *$ & $0.763 * *$ & $0.727 * *$ & $0.737 * *$ & $0.746^{* *}$ \\
\hline $\begin{array}{l}\text { Performance \& } \\
\text { Accountability }\end{array}$ & $0.624 * *$ & $0.661 * *$ & $0.644 * *$ & $0.662 * *$ & $0.683 * *$ \\
\hline Strategic Alignment & $0.595^{* *}$ & $0.620 * *$ & $0.634 * *$ & $0.688 * *$ & $0.689 * *$ \\
\hline Work Processes & $0.612 * *$ & $0.635 * *$ & $0.677 * *$ & $0.730 * *$ & $0.744 * *$ \\
\hline \multicolumn{6}{|l|}{ Work Performance } \\
\hline Teachers' Performance & $0.163 *$ & $0.178 *$ & $0.172 *$ & $0.157 *$ & $0.162 *$ \\
\hline
\end{tabular}

Second, the five domains of learning organization were found to have a moderate to a strong relationship with work commitment. Learning organizational culture is marginally and positively associated with job satisfaction, according to Karthikeyan \& Savarimuthu (2020). Furthermore, the organizational commitment was found to be positively connected with learning organization culture and job satisfaction, except for continuation commitment. This study helps leaders and human resource professionals to see organizational commitment, learning organization culture, and work satisfaction as critical variables that may be used in management, interventions, and practices. Erdem \& Ucar (2013) find a link between organizational commitment characteristics and the learning organization perception scale dimensions in their research.

Lastly, learning organization also significantly correlated with teacher's performance. Maligalig (2018) found that a shortage of qualified teachers contributes to the country's lowquality basic education. This outcome is consistent with the reforms outlined in the Basic Education Sector Reform Agenda (BESRA), especially in the Key Reform Thrust 2. There is 
a need to improve English, Math, and Science teachers' classroom performance to achieve higher learning results (Alvior, 2014). The findings back up Hamzah, Maidin, and Rahman (2011), who found that teachers had a generally favorable attitude toward information sharing and recognized its value in peer learning. However, it's worth noting that two major obstacles hinder teachers from learning. Individuals and internal and external assistance are three major kinds of interference in schools that prevent teachers from being inventive and creative. Teachers may believe that because bringing about systemic change in education would require so much collaboration, they should focus on improving what happens in their classroom. Overall, instructors' satisfaction with their supervisors' monitoring and work commitment impacts their productivity. The most significant impact was on school administrators to see their job fostering an environment where teachers can continue to learn.

\section{Conclusion}

Based on the finding, the following conclusions were drawn: work culture regarding supportive, innovative, and bureaucratic culture was deemed highly observed; the dimensions of learning organization practices were considered to be highly practiced; there is a high manifestation of work productivity in effective teaching and work commitment among public elementary teachers. Likewise, the teachers' work performance rating was very satisfactory; and there is a significant correlation between the three constructs of work culture and work productivity. A moderate association was observed with supportive, innovative work culture to work productivity. However, work performance shows no relationship with the work culture. Likewise, a strong association was seen between learning organization, effective teaching, work commitment, and teacher performance.

Since the study revealed that work culture and learning organization promotes work productivity, it is recommended that school administrators and the human resource department initiate activities such as team building, webinar series, or In-Service Training (INSET) that would encourage and develop supportive, innovative, and bureaucratic culture. This can also be a venue for the organization to promote its goals and visions.

With the limited number of samples, further studies can consider raising the number of schools by involving all seven (7) district school systems in the DepEd Division of San Pablo City. It has the potential to improve the quality and validity of the data collected and 
the outcomes' reliability and objectivity. Future researchers may also continue the study or conduct similar research in other areas of development since this study dealt only with the work culture and learning organization variables and the work productivity among public elementary teachers.

\section{References}

Almy, S., \& Tooley, M. (2012). Building and Sustaining Talent: Creating Conditions in High-Poverty Schools That Support Effective Teaching and Learning. Education Trust.

Alvior, C. (2014). The Basics of Social Research, Belmont, California: Wadsworth Cengage, pp. 303-04.

Bergström, E., \& Garcia Martinez, M. (2016). The Influence of Intrinsic and Extrinsic Motivation on Employee Engagement: A qualitative study of the perceptions of managers in public and private sector organizations. URN: urn:nbn:se:umu:diva123223

Boon, C., Eckardt, R., Lepak, D. P., \& Boselie, P. (2018). Integrating strategic human capital and strategic human resource management. The International Journal of Human Resource Management, 29(1), 34-67. https://doi.org/10.1080/09585192.2017.1380063

Burtscher, M. J., \& Manser, T. (2012). Team mental models and their potential to improve teamwork and safety: a review and implications for future research in healthcare. Safety Science, 50(5), 1344-1354. https://doi.org/10.1016/j.ssci.2011.12.033

Cansoy, R. \& Parlar, H. (2017). The Effect of Bureaucratic School Structure on Teacher Leadership Culture: A Mixed Study. Education Science: Theory and Practice. http://dx.doi.org/10.12738/estp.2017.6.0150

Cropper, P., Robinson, D., Farrell, M., Webster, R., Germain, J., Cummings, K., ... \& Benson, V. (2018). Technology-Based Learning in the Public Workforce System: Emerging Policy and Practices in States and American Job Centers.

DeMarco, A. L. (2018). The relationship between distributive leadership, school culture, and teacher self-efficacy at the middle school level. https://scholarship.shu.edu/dissertations/2594

Erdem, M., \& Ucar, I. H. (2013). Learning Organization Perceptions in Elementary Education in Terms of Teachers and the Effect of Learning Organization on Organizational Commitment. Educational Sciences: Theory and Practice, 13(3), 1527-1534. DOI: 10.12738/estp.2013.3.1693

Giovannelli, M. (2010). Relationship between reflective disposition toward teaching and effective teaching. The journal of educational research, 96(5), 293-309. DOI: 10.1080/00220670309597642

Hamzah, M. I. M., Maidin, F., \& Rahman, S. (2011). Supporting and inhibiting factors of creativity, innovation and wisdom among teachers in a learning organization. World Applied Sciences Journal, 15, 56-62. 
Hartiwi, H., Kozlova, A. Y., \& Masitoh, F. (2020). The Effect of Certified Teachers and Principal Leadership toward Teachers' Performance. International Journal Of Educational Review, 2(1), 70-88.

Kaiser, A., Fahrenbach, F., \& Martinez, H. (2021, January). Creating Shared Visions in Organizations-Taking an Organizational Learning and Knowledge Management Perspective. In Proceedings of the 54th Hawaii International Conference on System Sciences (p. 5186). DOI: 10.24251/HICSS.2021.632

Karthikeyan, S., \& Savarimuthu, I. D. A. (2020). RELATIONSHIP BETWEEN LEARNING ORGANIZATIONS AND ORGANIZATIONAL COMMITMENT A CRITICAL REVIEW-. International Journal of Management (IJM), 11(6).

Kim, W., Kim, J., Woo, H., Park, J., Jo, J., Park, S. H., \& Lim, S. Y. (2017). The relationship between work engagement and organizational commitment: Proposing research agendas through a review of empirical literature. Human Resource Development Review, 16(4), 350-376. https://doi.org/10.1177/1534484317725967

Latta, G. F. (2009). A process model of organizational change in cultural context (OC3 Model) The impact of organizational culture on leading change. Journal of $\begin{array}{lllll}\text { Leadership } \quad \& \quad \text { Organizational } \quad \text { Studies, } & 16(1),\end{array}$ https://doi.org/10.1177/1548051809334197

Maligalig, A.M. (2018). "Sinag teachers' summit," Sun Life Financial Philippines, Novotel Manila, Araneta Center, Quezon City, Philippines. DOI: 10.18178/ijiet.2020.10.2.1355

Manlow, V. (2010). Inventing the Future: Using the new media to transform a university from a teaching organization to a learning organization. Journal of Interactive Learning Research, 21(1), 47-64.

Mitchell, R. M. (2020). Enabling School Structure. Oxford Research Encyclopedia of Education.

Nisa, W. (2020). The Contribution of Professional Competence through the Work Discipline and Performance to Teacher Work Productivity in Public Elementary School of Tabunganen Subdistrict, Barito Kuala . Journal of K6 Education and Management, 3(2), 149-157. https://doi.org/10.11594/jk6em.03.02.06

Radda, A. A., Majidadi, M. A., \& Akanno, S. N. (2015). Employee engagement: The new model of leadership. Indian Journal of Management Science, 5(2), 17.

Sellar, S., \& Lingard, B. (2013). The OECD and global governance in education. Journal of education policy, 28(5), 710-725. https://doi.org/10.1080/02680939.2013.779791

Tomlinson, C.A. (2014). The Differentiated Classroom: responding to the Needs of All Learners $2^{\text {nd }}$ Edition. ASCD, Alexandria, VA USA. p.60-80.

Trinter, C. P., \& Hughes, H. E. (2021). Teachers as Curriculum Designers: Inviting Teachers into the Productive Struggle. RMLE Online, 44(3), 1-16. https://doi.org/10.1080/19404476.2021.1878417

Tulgar, A. T. (2019). Four Shades of Feedback: The Content of Feedback from Faculty Supervisor, Cooperating Teacher, Peers and Students in Practice Teaching and Its Effects on Self-Reflection and Self-Regulation. Alberta Journal of Educational Research, 65(3), 258-277.

Zmuda, A. (2004). Transforming schools: creating a culture of continuous improvement. Alexandria, VA: Association for Supervision and Curriculum Development press. 